Estudios Constitucionales, Año 14, No 1, 2016, pp. 61-94

ISSN 07180195

Centro de Estudios Constitucionales de Chile Universidad de Talca

"Teoría del control de convencionalidad"

Hernán Alejandro Olano García

\title{
TEORÍA DEL CONTROL DE CONVENCIONALIDAD ${ }^{1}$ Conventionality Control Theory
}

\author{
Hernán Alejandro Olano García* \\ Universidad de La Sabana \\ hernan.olano@unisabana.edu.co
}

RESUMEN: El autor, dentro de su linea de investigación en historia de las instituciones, desarrolla por vía de revisión los principales conceptos que llevan al Sistema Interamericano a hablar del Control de Convencionalidad, como concreción jurisdiccional de la garantía de aplicabilidad de las decisiones del Sistema Jurisdiccional Interamericano en el derecho interno.

ABSTRACT: The author, in his line of investigation into the history of institutions, develops the principal concepts that lead to the Inter-American System to talk about Conventionalitys Control, as a jurisdictional concretion of the guarantee of applicability of the decisions of the Jurisdictional Inter-American System in the internal Law.

Palabras Clave: Sistema Interamericano, Bloque de Constitucionalidad, Bloque de Convencionalidad, DD.HH., DIH, Corte Interamericana de Derechos Humanos, Comisión Interamericana, Tratados Internacionales.

KEYWORDS: Inter-American System, Block of Constitutionality, Block of Conventionality, HHRR, IHR, Inter-American Court of Human Rights, Inter-American Commission, International Agreements.

\section{INTRODUCCIÓN}

Este texto constituye un avance sobre el estado del arte y la formulación de un principio que cada día cobra más vigencia a nivel interamericano y panhispánico,

1 Trabajo recibido el 22 de septiembre de 2015 y aprobado el 27 de abril de 2016 . El presente trabajo forma parte de la línea de investigación en Historia de las Instituciones - I, que el autor desarrolla dentro del Grupo de Investigación en Derecho, Ética e Historia de las Instituciones "Diego de Torres y Moyachoque, Cacique de Turmequé". Dirección de Investigaciones de la Rectoría de la Universidad de La Sabana. Vigente desde el 30 de enero de 2016, registro DIN-HUM-052/2015.

* Abogado por la Universidad La Gran Colombia; Doctor magna cum laude en Derecho Canónico. Estancias postdoctorales en Derecho Constitucional como Becario de la Fundación Carolina en la Universidad de Navarra, España, y en Historia en el Departamento de Historia Medieval, de América y Contemporánea de la Universidad del País Vasco, como Becario de AUIP. Es Magíster en Relaciones Internacionales y Magíster en Derecho Canónico y se ha especializado en Derecho Administrativo, Derecho Constitucional, Derechos Humanos, Bioética y Liderazgo Estratégico Militar, en las universidades Complutense de Madrid, de La Sabana, Centro de Estudios Militares y Centro de Estudios Políticos y Constitucionales de Madrid. Ha sido 
el control de convencionalidad, que ya se incorpora sustancialmente a nuestras jurisdicciones latinoamericanas como fuente principal para la interpretación del Derecho Internacional de los Derechos Humanos, bajo la hipótesis: ¡están preparados los jueces para aplicar en los países del Sistema Interamericano el Control de Convencionalidad?

La interrelación de los tribunales internacionales en materia de derechos humanos y los tribunales nacionales es lo que se ha venido a denominar control de convencionalidad, surgido a partir del aporte de la jurisprudencia interamericana, e "implica valorar los actos de la autoridad interna a la luz del Derecho internacional de los derechos humanos, expresado en tratados o convenciones" 2 , aunque no ha logrado llegar a la "periferia" del derecho: los jueces de menor jerarquía.

El control de convencionalidad puede darse a nivel tanto internacional como interno y, cuando se utiliza bien, contribuye a que las fuentes internas e internacionales del derecho vigente en cada Estado puedan aplicarse por todas las autoridades de manera ordenada, lógica, armónica y coherente. Así, entonces, la premisa del control de convencionalidad "reside en la idea -que rige el comportamiento del Estado parte en un tratado internacional- de que la norma de este carácter obliga al Estado en su conjunto. Es éste, y no sólo algunos órganos o agentes, quien asume los compromisos y los deberes de carácter internacional. Así las cosas, ningún sector del Estado -nacional o regional, federal o local- podría sustraerse al cumplimiento de esos deberes; en consecuencia, los tribunales internos deberían analizar la observancia de aquéllos y ajustar sus decisiones a estos imperativos. De ahí que ejerzan un control de convencionalidad que se extiende tanto a la actuación de órganos no jurisdiccionales como a la de órganos jurisdiccionales, cuando esta actuación queda sujeta a revisión por parte del tribunal que ejerce el control"3.

Becario del Excelentísimo Ayuntamiento de Cádiz en 2011. Es el Director del Programa de Humanidades en la Facultad de Filosofía y Ciencias Humanas de la Universidad de La Sabana, donde es también el Director de Estudiantes de la Carrera de Filosofía, Director del Departamento de Historia y Estudios Socio Culturales y Director del Grupo de Investigación en Derecho, Ética e Historia de las Instituciones "Diego de Torres y Moyachoque, Cacique de Turmequé", categoría C de Colciencias. Es Investigador Asociado (I) de Colciencias e Investigador de la Cátedra Garrigues de la Universidad de Navarra. Es el Vice Cónsul honorario de la República de Chipre en Colombia. Miembro de Número de la Academia Colombiana de Jurisprudencia; Miembro Correspondiente (electo) de la Academia Colombiana de la Lengua; Miembro Correspondiente extranjero de la Academia Chilena de Ciencias Sociales, Políticas y Morales y, Miembro de Honor del muy Ilustre, Benemérito y Bicentenario Colegio de Abogados de Lima.

2 García Ramírez y Morales Sánchez (2013), p. 621.

3 García Ramírez y Morales Sánchez (2013), p. 622. 
El control de convencionalidad en el Sistema Interamericano sirve de paradigma para demostrar que no sólo la ley cumple efectos generales en cada país, sino también las sentencias y decisiones que los comprometen internacionalmente, pasando de un Estado Social de Derecho, de carácter eminentemente nacional, donde impera un control de legalidad y un control de constitucionalidad, a un Estado Convencional de Derecho, en el cual se habla de un Control de Convencionalidad. De ahí se deriva que, a lo largo del artículo, encontremos que la cosa juzgada en las decisiones jurisdiccionales ya no se configuraría como derivada de la Constitución (cosa juzgada constitucional), ni de la ley (cosa juzgada legal), sino de la Convención (cosa juzgada convencional).

Ojalá que la jurisprudencia de cada Suprema Corte o Tribunal Constitucional avance en la línea de amplificar los espacios de funcionamiento de la fiscalización de las pretermisiones anticonstitucionales e inconvencionales para que pueda cobrar verdadera vigencia el Control de Convencionalidad, generando guías para que los operadores judiciales inferiores lo apliquen de conformidad con el trámite impuesto.

\section{Desarrollo}

$\mathrm{Al}$ interior del Sistema Interamericano, específicamente de la Corte Interamericana de Derechos Humanos (en adelante CIDH), ha nacido el control de convencionalidad como una herramienta jurídica, dinámica, adecuada, útil y fundamental que surge de las convenciones o tratados internacionales sobre derechos humanos como primera fuente de juridicidad y busca lograr el cumplimiento y debida implementación de la sentencia internacional. El control de convencionalidad es un término creado por la CIDH y consustancial a esa jurisdicción, que surge en el año 2003, cuando, si bien no llegó a dársele el alcance que posteriormente obtuvo, el juez Sergio García Ramírez, en el Caso Myrna Mack Chang vs. Guatemala ${ }^{4}$, emitió su voto razonado en los siguientes términos:

Para los efectos de la Convención Americana y del ejercicio de la jurisdicción contenciosa de la Corte Interamericana, el Estado viene a cuentas en forma integral, como un todo. En este orden, la responsabilidad es global, atañe al Estado en su conjunto y no puede quedar sujeta a la división de atribuciones que señale el Derecho interno. No es posible seccionar internacionalmente al Estado, obligar ante la Corte sólo a algunos de sus órga-

4 Myrna Mack Chang con Guatemala. Corte IDH., sentencia de 25 de noviembre de 2003, voto razonado del juez Sergio García Ramírez, párrafo 27. 
nos, entregar a éstos la representación del Estado en el juicio -sin que esa representación repercuta sobre el estado en su conjunto-y sustraer a otros de este régimen convencional de responsabilidad, dejando sus actuaciones fuera del "control de convencionalidad" que trae consigo la jurisdicción de la Corte internacional.

Sin embargo, aquí García utiliza la locución "control de convencionalidad” para hablar del despliegue funcional de la $\mathrm{CIDH}$ como una especie de tribunal supranacional convencional. Así, como dicen García Belaunde y Palomino Manchego, "el control propio, original o externo de convencionalidad recae en el tribunal supranacional llamado a ejercer la confrontación entre los actos domésticos y las disposiciones convencionales, en su caso, con el propósito de apreciar la compatibilidad entre aquéllos y éstas -bajo el imperio del Derecho Internacional de los Derechos Humanos- y resolver la contienda a través de la sentencia declarativa y condenatoria que corresponda" 5 . La Corte Interamericana ha manifestado que este control de convencionalidad "ha de practicarse dentro de las atribuciones de las autoridades jurisdiccionales y conforme a los procedimientos establecidos en la legislación interna"6.

Luego, en el Caso Tibi vs. Ecuador7, se explicó que "el Tribunal Interamericano analiza los actos que llegan a su conocimiento en relación con normas, principios y valores de los tratados en los que se funda su competencia contenciosa, resolviendo acerca de la convencionalidad de tales actos, pretendiendo conformar esa actividad al orden internacional acogido en la convención fundadora de la jurisdicción interamericana y aceptado por los Estados Partes en el ejercicio de su soberanía"8.

Más tarde, la CIDH en el año 2006, a través de la sentencia del Caso Almonacid Arellano et al. vs. Chile', un verdadero hito jurisprudencial, manifestó que:

124. La Corte es consciente que los jueces y tribunales internos están sujetos al imperio de la ley y, por ello, están obligados a aplicar las disposiciones vigentes en el ordenamiento jurídico. Pero cuando un Estado ha ratificado un tratado internacional como la Convención Americana, sus jueces, como parte del aparato del Estado, también están sometidos a ella, lo que les obliga a velar porque los efectos de las disposiciones de la Convención

5 García y Palomino, (2013) p. 225.

6 García Ramírez y Morales Sánchez (2013), p. 623.

7 Tibi con Ecuador. Corte IDH., sentencia de excepciones preliminares, fondo, reparaciones y costas de 7 de septiembre de 2004, Serie C, \# 114, párrafo 3.

8 BAZÁN (2014), p. 297.

9 Almonacid Arellano et al con Chile. Corte IDH. Chile, sentencia de 26 de septiembre de 2006, párrafo 124. 
no se vean mermadas por la aplicación de leyes contrarias a su objeto y fin, y que desde un inicio carecen de efectos jurídicos. En otras palabras, el Poder Judicial debe ejercer una especie de "control de convencionalidad" entre las normas jurídicas internas que aplican en los casos concretos y la Convención Americana sobre Derechos Humanos. En esa tarea, el Poder Judicial debe tener en cuenta no solamente el tratado, sino también la interpretación que del mismo ha hecho la Corte interamericana, intérprete última de la Convención Americana.

Este fallo es analizado por Víctor Bazán cuando dice que "en tal fallo el Tribunal Interamericano fija a los poderes judiciarios de los Estados (ordinarios y/o constitucionales, según corresponda) la misión de concretar el control de convencionalidad de las normas jurídicas internas que aplican en los casos concretos frente a la $\mathrm{CADH}$, tomando en consideración al efecto no sólo la literalidad de dicho pacto sino la lectura que del mismo ha realizado la Corte, que -como se sabe- es el intérprete último de aquél. Realza, así, la operatividad de la pauta de interpretación conforme a la CADH como estándar hermenéutico a respetar y resguardar por parte de los órganos jurisdiccionales vernáculos"10.

Así, la CIDH posee un control propio, original y externo, que hace que "en definitiva, ese control le compete, original y exclusivamente a la Corte, cuando se trata de examinar casos de los que aquella conoce y a los que aplica normas conforme a su propia competencia material" 11 . En ese sentido, afirma Claudio Nash Rojas ${ }^{12}$ que el control de convencional debe ser entendido "como la obligación que tienen los jueces de cada uno de los Estados Partes de efectuar no sólo un control de legalidad y de constitucionalidad en los asuntos de su competencia, sino de integrar en el sistema de sus decisiones las normas contenidas en la Convención Americana de Derechos Humanos (...) y los estándares desarrollados por la jurisprudencia", aunque cabe indicar que no existe una jerarquía de derechos en la $\mathrm{CADH}^{13}$, sino que hay unos que son más protegidos que otros en determinado momento y, particularmente, cuando hay estados de excepción constitucional.

Son dos los fundamentos jurídicos del control de convencionalidad, los cuales poseen origen en el derecho internacional: i) efecto útil de las obligaciones internacionales, que deben ser cumplidas de buena fe, y ii) la prohibición de alegar el

10 BAZÁN (2013), p. 233.

11 García y Palomino (2013), p. 225.

12 NASH (2013), p. 494.

13 Villagrán Morales y otros con Guatemala (Caso <niños de la calle>) Corte IDH., sentencia de 26 de mayo de 2001. 
derecho interno para incumplirlas, conforme al artículo 27 de la Convención de Viena sobre el Derecho de los Tratados ${ }^{14}$. Ese artículo 27 apareció en el párrafo 125 de la Sentencia Almonacid Arellano, cuando la CIDH dijo que "según el derecho internacional las obligaciones que éste impone deben ser acatadas de buena fe y no puede invocarse para su incumplimiento el derecho interno" 15 .

El mismo Sagués ${ }^{16}$ identificó igualmente las alternativas existentes cuando el ordenamiento nacional excluye la intervención de ciertos juzgadores para llevar a cabo el control de constitucionalidad y no se ha previsto una vía procesal para remitir la controversia al juzgador facultado para ejercer el control. Dichas alternativas son: i) como ruta preferible, la reforma constitucional o legislativa, según el caso; ii) mientras esto ocurre, reconocer pretorianamente a todos los jueces capacidad para ejercer el control de convencionalidad (solución del "control difuso") y iii) diseñar - pretorianamente también- un mecanismo de elevación del caso al órgano constitucionalmente facultado para operar el control de constitucionalidad.

Ese primer acercamiento a lo que debe ser el control de convencionalidad meses más tarde se ratificó en el Caso Trabajadores Cesados del Congreso (Aguado Alfaro et al.) vs. Perú17, agregando que ex officio (aunque también a petición de Parte), los jueces y, en general, los órganos del Poder Judicial deben ejercer no solamente el control de constitucionalidad, sino también el de convencionalidad entre las normas internas y la Convención Americana en el marco de sus respectivas competencias y de las regulaciones procesales correspondientes. De esa manera, el control de convencionalidad comenzó su andadura y desarrollo en la dogmática de los derechos fundamentales, para hacer cumplir los imperativos mandatos jurisdiccionales de la Corte Interamericana de Derechos Humanos-CIDH. La sentencia citada incluye esta apreciación:

Cuando un Estado ha ratificado un tratado internacional como la Convención Americana, sus jueces también están sometidos a ella, lo que les obliga a velar porque el efecto útil de la Convención no se vea mermado o anulado por la aplicación de leyes contrarias a sus disposiciones, objeto y fin. En otras palabras, los órganos del Poder Judicial deben ejercer no sólo un control de constitucionalidad, sino también de "convencionalidad" ex officio

\footnotetext{
14 SAGUÉs (2010), p. 452.

15 Hernández (2013), p. 642.

16 García Ramírez y Morales Sánchez (2013) pp. 624-625.

17 Caso Trabajadores Cesados del Congreso (Aguado Alfaro et al.) con Perú Corte IDH., sentencia de 24 de noviembre de 2006, párrafo 128.
} 
entre las normas internas y la Convención Americana, evidentemente en el marco de sus respectivas competencias y de las regulaciones procesales correspondientes. Esta función no debe quedar limitada exclusivamente por las manifestaciones o actos de los accionantes en cada caso concreto, aunque tampoco implica que ese control deba ejercerse siempre, sin considerar otros presupuestos formales y materiales de admisibilidad y procedencia de ese tipo de acciones.

En este tercer caso, se pudo apreciar que la CIDH señaló que el control de convencionalidad debe ejercerse, incluso de oficio, por los jueces de los Estados Parte, "dentro del ámbito de sus competencias y funciones de la magistratura"18, al igual que de acuerdo con las regulaciones procesales correspondientes, como lo ratificó la CIDH en el Caso Cabrera García y Montiel Flores vs. México ${ }^{19}$.

Así las cosas, hoy en día puede afirmarse que la juridicidad derivada del control de convencionalidad posee dos requisitos: "Primera, que la Convención internacional positiviza las exigencias de justicia que como derechos humanos se formulan en torno a la Persona; y segunda, se ha de reconocer que con base en ese contenido positivado, la Convención -y no la Constitución- define lo que es jurídicamente válido en el seno de un Estado" 20 .

Tratadistas han expresado que hay entonces, con base en estos primeros fallos, unos elementos centrales del control de convencionalidad ${ }^{21}$ :

a. Existe una obligación del poder judicial de cumplir con la normativa internacional que el Estado ha recepcionado internamente y que por tanto ha pasado a ser parte del sistema normativo interno.

b. Éste es un ejercicio hermenéutico que debe buscar la efectividad de los derechos consagrados convencionalmente y evitar que el Estado incurra en responsabilidad internacional.

c. Las normas contrarias a la Convención no pueden tener efectos en el ámbito interno, toda vez que dichas normas, incompatibles con las obligaciones internacionales, constituyen un ilícito internacional que hace responsable al Estado.

d. Para realizar dicho ejercicio interpretativo el juez debe tener en consideración la jurisprudencia de la CIDH.

18 NASH (2013), p. 497.

19 Caso Cabrera García y Montiel Flores con México Corte IDH., Sentencia de excepción preliminar, fondo, reparaciones y costas, de 26 de noviembre de 2010, Serie C, \# 220, párrafo 225.

20 Álvarez et. al., (2013), p. 84.

21 NASH (2013), p. 496. 
En el ámbito interamericano, la CADH se ha sobrepuesto a las constituciones nacionales, así como a toda norma infraconstitucional en un Estado, de tal suerte que todo el ordenamiento jurídico debe adecuarse, según el artículo de la $\mathrm{CADH}$, a ésta, no obstante que esa norma convencional no expresa cuáles son las medidas pertinentes para la adecuación del derecho interno a la misma.

En el Caso La Cantuta vs. Perú ${ }^{22}$, la CIDH interpretó que la adecuación de los ordenamientos internos a la CADH implica la adopción de medidas en dos vertientes: “i) la supresión de las normas y prácticas de cualquier naturaleza que entrañen violación a las garantías previstas en la Convención o que desconozcan los derechos allí reconocidos u obstaculicen su ejercicio, y ii) la expedición de normas y el desarrollo de prácticas conducentes a la efectiva observancia de dichas garantías".

Otro aspecto a apreciar es que las decisiones de la CIDH se superponen a las del tribunal de cierre de cada país (las Cortes o Tribunales constitucionales), razón por la cual esos órganos nacionales deben también observar las prescripciones de la $\mathrm{CIDH}$, siguiendo también las disposiciones de la $\mathrm{CADH}$, todo lo cual permite señalar tres elementos del control de convencionalidad: "a) se crea la obligación jurídica a los jueces de velar por la vigencia de la Convención inaplicando leyes que, siendo constitucionales, la puedan contravenir; b) el parámetro de control no sólo serán las disposiciones convencionales sino también las interpretaciones que de las mismas haya presentado la $\mathrm{CIDH}$ en su jurisprudencia; c) el objeto de control es referido como 'las normas internas', las cuales no sólo se limitan a las leyes sino que abarcan toda decisión normativa, incluso la Constitución misma”23.

En Costa Rica, un ilustre constitucionalista ${ }^{24}$, siguiendo al doctrinante alemán Simón, propone una serie de supuestos y límites del principio de interpretación conforme a la Constitución para el control de convencionalidad, los cuales son los siguientes:

i) Toda interpretación conforme a la Convención presupone, como algo evidente, que la norma en cuestión es susceptible de interpretación en general. Las normas con un contenido unívoco son o bien compatibles, o bien incompatibles con la Convención; en estos casos no se puede llegar a la interpretación conforme a la Convención que se sitúa entre ambos extremos.

22 Caso La Cantuta con Perú Corte IDH, sentencia de 29 de noviembre de 2006, párrafo 172.

23 Álvarez, et. al., (2013), p. 86.

24 Hernández (2013), pp. 654-655. 
ii) La interpretación conforme a la Convención "no juega ningún papel, si la decisión depende exclusivamente de la aplicación de la propia Convención”.

iii) No tiene sentido una interpretación conforme a la Convención, si una norma la viola en cualquier interpretación imaginable.

iv) Las normas convencionales no deben ser interpretadas según la máxima de que la legislación interna tiene que subsistir. Ello supondría una interpretación de la CADH conforme al ordenamiento interno.

La relevancia del control de convencionalidad "resalta cuando se toman en cuenta las implicaciones o consecuencias de la inobservancia del Derecho internacional de los derechos humanos por la jurisdicción interna: la aplicación del CIDH omitida por la jurisdicción interna, que desdeña la oportunidad para asumirla, será la practicada por la jurisdicción internacional, que actuará subsidiariamente, en su propia oportunidad, para aplicar las disposiciones jurídicas internacionales quebrantadas o desatendidas" 25 .

Se puede leer en el Caso Cabrera García y Montiel Flórez vs. México ${ }^{26}$ que en materia de generalización de la aplicación de las decisiones de la $\mathrm{CIDH}$, los jueces de los Estados Parte deben aplicar dichas disposiciones, puesto que:

Este Tribunal ha establecido en su jurisprudencia que es consciente que las autoridades internas están sujetas al imperio de la ley y, por ello, están obligadas a aplicar las disposiciones vigentes en el ordenamiento jurídico. Pero cuando un estado es Parte de un tratado internacional como la Convención Americana, todos sus órganos, incluidos sus jueces, también están sometidos a aquél, lo cual les obliga a velar porque los efectos de las disposiciones de la Convención no se vean mermados por la aplicación de normas contrarias a su objeto y fin. Los jueces y órganos vinculados a la administración de justicia en todos los niveles están en la obligación de ejercer ex officio un "control de convencionalidad" entre las normas internas y la Convención Americana, evidentemente en el marco de sus respectivas competencias y de las regulaciones procesales correspondientes. En esta tarea, los jueces y órganos judiciales vinculados a la administración de justicia deben tener en cuenta no solamente el tratado, sino también la interpretación que del mismo ha hecho la Corte Interamericana, intérprete última de la Convención Americana.

$\mathrm{Y}$ es que la $\mathrm{CIDH}$ tiene una competencia muy importante, cual es la de supervisar el cumplimiento de sus propias decisiones, especialmente en las decisiones de fondo y reparaciones, para lo cual ha implementado audiencias

25 García Ramírez y Morales Sánchez (2013), p. 632.

26 Caso Cabrera García y Montiel Flórez con México Corte IDH, sentencia del 26 de noviembre de 2010, párrafo 225. 
públicas o privadas donde escucha el parecer de la Comisión Interamericana y analiza las posiciones del Estado, las víctimas y sus representantes ${ }^{27}$. Esto, ya que las decisiones de los organismos de carácter jurisdiccional internacional poseen la fuerza de cosa juzgada internacional y deben ser cumplidas por su carácter inimpugnable, ya que producen eficacia vinculante sin que se requiera ningún tipo de procedimiento o exequatur para ello, como se desprende de la interpretación del artículo 67 de la CADH, lo mismo que del 68, el cual se refiere a la inmutabilidad que descansa en los principios generales del derecho de seguridad jurídica y paz social, al permitir certeza a las partes. Eso se explica en el sentido de que la sentencia interamericana "adquiere la autoridad de la cosa juzgada internacional, despliega los contenidos y efectos de la sentencia en dos dimensiones: a) de manera subjetiva y directa hacia las Partes en la controversia internacional; y b) de manera objetiva e indirecta hacia todos los estados Parte en la Convención Americana"28.

Además, la $\mathrm{CIDH}$ ha reiterado en sus decisiones que el control de convencionalidad debe ejercerse bajo el principio de legalidad, al igual que con base en los siguientes "controles", así definidos por el autor del término ${ }^{29}$ :

i) Control judicial de convencionalidad para establecer la conformidad entre la norma internacional y nacional (no hay salvedad sobre el carácter de la norma interna: legal o reglamentaria);

ii) Control a cargo de los órganos judiciales, no de los administrativos. Aunque no hay que olvidar el giro en la jurisprudencia interamericana que incluye a los "órganos vinculados a la administración de justicia en todos los niveles";

iii) Control ejercido de oficio, motu proprio, por el órgano que cumpla esta función, sin necesidad de requerimiento o instancia de una parte procesal, lo cual pone en movimiento, asimismo, el principio jura novit curia y la suplencia frente a la deficiencia de la queja;

iv) Control ejercido en los términos de la competencia del órgano que pretende realizarlo (y que debe estar facultado, en consecuencia, para esta misión: principio de legalidad en cuanto a las atribuciones específicas del juzgador);

v) Control cumplido conforme a un procedimiento regulado (que debe hallarse previsto, para ese efecto, en la ley: principio de legalidad a propósito del procedimiento).

27 Ferrer Mac-Gregor (2013), p. 618.

28 Ferrer Mac-Gregor (2013), p. 633.

29 García Ramírez y Morales Sánchez (2013), p. 634. 
De la misma forma, la CIDH ha expresado ${ }^{30}$ que los Estados Americanos han dispuesto un "sistema de garantía colectiva", lo cual quiere decir que "los estados Parte del Pacto de San José deben procurar todos los esfuerzos para que abonen al cumplimiento de las sentencias de la CIDH"31.

Ese sistema de garantía colectiva, siempre y cuando se emplee bien, hace también responsable de la aplicación de la CADH y de las decisiones de la $\mathrm{CIDH}$ a toda autoridad pública, pues la protección de los derechos humanos constituye un límite infranqueable a la regla de las mayorías, es decir, "a la esfera de lo 'susceptible de ser decidido' por parte de las mayorías en instancias democráticas, en las cuales también debe primar un 'control de convencionalidad', que es función y tarea de cualquier autoridad pública y no sólo del Poder Judicial...”, como lo establece el Caso Gelman vs. Uruguay ${ }^{32}$, y, "puede contribuir a la aplicación armónica, ordenada y coherente del derecho vigente en el Estado, abarcando a sus fuentes internas e internacionales" 33 .

Sin embargo, el control de convencionalidad también ha surgido del déficit de aplicabilidad en el ámbito interno de las decisiones de la CIDH, ya que las autoridades locales de la rama judicial desconocen que deben aplicar las obligaciones que surgen de cada uno de los fallos de la CIDH por estar incorporadas al derecho nacional de los Estados Parte.

Es que en los últimos veinticinco años, de manera particular, se ha venido dando una internacionalización del derecho constitucional, a la vez que una constitucionalización del derecho interno, de modo tal que los mecanismos de protección de los derechos fundamentales han venido a crear un solo y extenso cuerpo normativo y jurisprudencial.

Hay que advertir que el control de convencionalidad se da en primer lugar en el ámbito de la CIDH para expulsar de los ordenamientos internos disposiciones que vayan en contra de la $\mathrm{CADH}$, como se aprecia en el Caso Vargas Areco vs. Paraguay ${ }^{34}$, donde se precisó que la CIDH "tiene a su cargo el 'control

30 Corte IDH. Supervisión de Cumplimiento de sentencia. Resolución de la Corte Interamericana de Derechos Humanos de 23 de noviembre de 2012. Caso Apiz Barrera et. al vs. Venezuela, considerandos 46 y 47.

31 Ferrer Mac-Gregor (2013), p. 658.

32 Caso Gelman con Uruguay Corte IDH, sentencia de 24 de febrero de 2011, párrafo 239.

33 BAZÁN (2014), p. 296.

34 Caso Vargas Areco con Paraguay Corte IDH, sentencia de fondo, reparaciones y costas de 26 de septiembre de 2006, Serie C, \# 155, párrafos 6 y 7. Fue fallada el mismo día del Caso Almonacid Arellano vs. Chile. 
de convencionalidad' fundado en la confrontación entre el hecho realizado y las normas de la Convención Americana", pudiendo sólo "confrontar los hechos internos -leyes, actos administrativos, resoluciones jurisdiccionales, por ejemplo- con las normas de la Convención y resolver si existe congruencia entre aquéllos y éstas, para determinar, sobre esa base, si aparece la responsabilidad internacional del estado por incumplimiento de sus obligaciones de la misma naturaleza”.

En otros dos casos, Caso López Mendoza vs. Venezuela ${ }^{35}$ y Atala Riffo vs. Chile ${ }^{36}$, la CIDH sentó la regla según la cual, con base en el control de convencionalidad, es necesario que las interpretaciones judiciales y administrativas y las garantías judiciales se apliquen adecuándose a los principios establecidos en su jurisprudencia ${ }^{37}$.

Es decir que, en el ámbito interno de los Estados Parte, los operadores jurídicos deberían en primer lugar analizar sus casos para que sean compatibles con la CADH y, dado el caso, aplicar las sentencias de la CIDH, que generan criterios interpretativos con base en los artículos 1.1, 2 y 29 de la CADH, que dicen así.

Artículo 1. Obligación de Respetar los Derechos

1. Los Estados Partes en esta Convención se comprometen a respetar los derechos y libertades reconocidos en ella y a garantizar su libre y pleno ejercicio a toda persona que esté sujeta a su jurisdicción, sin discriminación alguna por motivos de raza, color, sexo, idioma, religión, opiniones políticas o de cualquier otra indole, origen nacional o social, posición económica, nacimiento o cualquier otra condición social.

Artículo 2. Deber de Adoptar Disposiciones de Derecho Interno

Si el ejercicio de los derechos y libertades mencionados en el artículo 1 no estuviere ya garantizado por disposiciones legislativas o de otro carácter, los Estados Partes se comprometen a adoptar, con arreglo a sus procedimientos constitucionales y a las disposiciones de esta Convención, las medidas legislativas o de otro carácter que fueren necesarias para hacer efectivos tales derechos y libertades.

35 Caso López Mendoza con Venezuela Corte IDH, Sentencia de fondo, reparaciones y costas del 1 de septiembre de 2011, Serie C, \# 233, párrafo 228.

36 Caso Atala Riffo con Chile Corte IDH, Sentencia de fondo, reparaciones y costas del 24 de febrero de 2012, Serie C \# 239, párrafo 284.

37 BAZÁN (2014), p. 302. 
Artículo 29. Normas de Interpretación

Ninguna disposición de la presente Convención puede ser interpretada en el sentido de:

a) permitir a alguno de los Estados Partes, grupo o persona, suprimir el goce y ejercicio de los derechos y libertades reconocidos en la Convención o limitarlos en mayor medida que la prevista en ella;

b) limitar el goce y ejercicio de cualquier derecho o libertad que pueda estar reconocido de acuerdo con las leyes de cualquiera de los Estados Partes o de acuerdo con otra convención en que sea Parte uno de dichos Estados;

c) excluir otros derechos y garantías que son inherentes al ser humano o que se derivan de la forma democrática representativa de gobierno, y

d) excluir o limitar el efecto que puedan producir la Declaración Americana de Derechos y Deberes del Hombre y otros actos internacionales de la misma naturaleza.

Las normas nos llevan a afirmar que los Estados deben siempre tener presente la promoción, protección y desarrollo de los derechos humanos y organizar lo pertinente para que los jueces, fiscales y defensores permitan a las personas tanto el ejercicio como el goce pleno y efectivo de los derechos consagrados en la CADH y apliquen las decisiones de la CIDH, para que "haya conformidad entre los actos internos y los compromisos internacionales contraídos por el Estado"38.

Esto se trató además en los casos Masacre de Santo Domingo vs. Colombia y Gelman vs. Uruguay, en los cuales se coincide por parte de la CIDH en afirmar que es "obligación propia de todo poder, órgano o autoridad del Estado Parte en la Convención (...) controlar que los derechos humanos de las personas sometidas a su jurisdicción sean respetados y garantizados".

$\mathrm{Y}$ es que los Estados Parte muchas veces quieren hacerse los de la vista gorda con los compromisos que asumen, sin darse cuenta que desde la expedición de la Convención de Viena de Derecho de los Tratados de 1969, en sus artículos 53 y 64, se aplica universalmente el principio pacta sunt servanda, que genera la obligación de cumplir los imperativos mandatos de los tratados y más cuando éstos se refieran a la protección de los derechos fundamentales:

Artículo 53. Tratados que están en oposición con una norma imperativa de derecho internacional general ("jus cogens"). Es nulo todo tratado que, en el momento de su celebración, esté en oposición con una norma imperativa de derecho internacional

38 NASH (2013), p. 494. 
general. Para los efectos de la presente Convención, una norma imperativa de derecho internacional general es una norma aceptada y reconocida por la comunidad internacional de Estados en su conjunto como norma que no admite acuerdo en contrario y que sólo puede ser modificada por una norma ulterior de derecho internacional general que tenga el mismo carácter.

64. Aparición de una nueva norma imperativa de derecho internacional general ("jus cogens"). Si surge una nueva norma imperativa de derecho internacional general, todo tratado existente que esté en oposición con esa norma se convertirá en nulo y terminará.

En el artículo 53 se encuentra la imperatividad de la norma internacional y, en el 64, lo que Víctor Bazán ha denominado el ius cogens superviviente ${ }^{39}$, pues se refiere a las normas de carácter imperativo que vayan surgiendo en la sociedad internacional y que, en la medida en que vayan siendo aceptadas por los Estados Parte, se hacen obligatorias para ellos dentro de su ordenamiento interno. Continúa Bazán diciendo que "La aserción puede corroborarse, por ejemplo, cuando argumenta que aquél cobija al principio de igualdad ante la ley, igual protección ante la ley y no discriminación; a la proscripción de tortura y de tratos crueles, inhumanos o degradantes; y al derecho de acceso a la justicia en los ámbitos nacional e internacional”. Entonces, el ius cogens se extiende también a aquellos postulados aceptados por las naciones en el ámbito interno.

En el Caso Velásquez Rodríguez vs. Honduras ${ }^{40}$, la $\mathrm{CIDH}$ señaló respecto a la obligación de garantía lo siguiente: "Esta obligación implica el deber de los Estados Partes de organizar todo el aparato gubernamental y, en general, todas las estructuras a través de las cuales se manifiesta el ejercicio del poder público, de manera tal que sean capaces de asegurar jurídicamente el libre y pleno ejercicio de los derechos humanos".

Pero, cabe indicar, que la misma CIDH amplió la aplicabilidad de la expresión control de convencionalidad a todos aquellos documentos que forman parte del corpus iuris interamericano y convencional, dentro del cual también están incluidos no sólo su esencia, que es la CADH-Pacto de San José, sino también, entre otros, la Declaración Americana de Derechos y Deberes del Hombre y otros actos internacionales de la misma naturaleza (art. 29 letra d) CADH). El juez constitucional ha sido enfático en exigir que estas normas convencionales deben reconocer un derecho humano, con lo cual, estaríamos ante un elenco bastante generoso y variopinto de tratados internacionales, de carácter universal o regional,

39 BAZÁN (2013), p. 293.

40 Caso Velásquez Rodríguez con Honduras Corte IDH, sentencia de 28 de julio de 1988, párrafo 166. 
que sirve como parámetro de interpretación de la normatividad interna. Entre ellas, forman parte:

- La Declaración Universal de Derechos Humanos de la ONU ${ }^{41}$;

- La misma Declaración Americana de los Derechos del Hombre y el Ciudadano-Pacto de San José de Costa Rica de 1969, en lo que se refiere al soft law ${ }^{42}$, entendido como tal soft law el término acuñado por Lord McNair y conocido como "derecho suave", por el que yo entiendo y defino el numeroso conjunto de instrumentos, resoluciones o recomendaciones, códigos de conducta, declaraciones, catálogos o lineamientos no obligatorios o no vinculantes de diferentes organismos internacionales, particularmente de la Asamblea General de las Naciones Unidas (AGNU), constituida en una especie de "legislador universal", que comprenden principios, reglas y líneas de acción sobre diversos temas de Derechos Humanos, Medio Ambiente, Colonialismo, etc.;

- El Pacto Internacional de Derechos Civiles y Políticos;

- El Pacto Internacional de Derechos Económicos, Sociales y Culturales, Pidesc, junto con el Protocolo Adicional de San Salvador, Sobre Derechos Económicos, Sociales y Culturales;

- La Convención contra la Tortura y otros Tratos o Penas Crueles, Inhumanos o Degradantes;

- La Convención Interamericana sobre Desaparición Forzada de Personas;

- La Convención para la Prevención y Sanción del Delito de Genocidio;

- Los Convenios de la OIT, en especial, el Convenio 21 sobre emigrantes; los Convenios 29 y 105, sobre Abolición del Trabajo Forzoso; los Convenios 81 y

41 Expedida el 10 de diciembre de 1948.

42 Entre muchos documentos, podemos mencionar la Declaración de Estocolmo sobre Medio Humano; la Declaración de Río sobre Medio Ambiente y Desarrollo; la Declaración de Dublín sobre el Agua y el Desarrollo Sostenible; la Declaración de Principios sobre Derechos Humanos y Medio Ambiente; la Declaración de Vizcaya sobre el Derecho al Medio Ambiente; el Protocolo de Bioseguridad de Montreal; la Carta de la Tierra; los Objetivos del Milenio-ODM; la Declaración sobre la concesión de la independencia a los países y pueblos coloniales; el Código de Conducta de los funcionarios encargados de hacer cumplir la ley; los principios básicos sobre la función de los abogados; los principios básicos relativos a la independencia de la judicatura; las Directrices de Naciones Unidas para la Prevención de la Delincuencia Juvenil (Directrices de Riad); las Reglas de Tokio o Reglas Mínimas de las Naciones Unidas sobre las Medidas no privativas de la Libertad; las Reglas Mínimas de las Naciones Unidas para la Administración de la Justicia de Menores (Reglas de Beijing); las Reglas de Naciones Unidas para la Protección de los Menores Privados de la Libertad; el Conjunto de Principios para la Protección de todas las personas sometidas a cualquier forma de detención o prisión; los Principios Básicos para el Tratamiento de los Reclusos; las Reglas Mínimas para el Tratamiento de los Reclusos; y un largo etc. 
129 sobre Inspección del Trabajo; Convenios 87 y 98, sobre Libertad Sindical y Protección del Derecho de Sindicalización y Negociación Colectiva; el Convenio 116 sobre la Preparación de las memorias sobre la Aplicación de convenios por parte del Consejo de Administración de la OIT; el Convenio 138 sobre edad mínima de Admisión al empleo; el Convenio $154^{43}$ sobre Fomento de la Negociación Colectiva, el Convenio sobre la Readaptación Profesional y el Empleo de Personas Inválidas; el Convenio 160 sobre Estadísticas en el Trabajo; el Convenio 182, sobre Prohibición de las peores formas de trabajo infantil y la Acción inmediata para su eliminación; y, finalmente, el Convenio OIT 169 sobre Pueblos Indígenas y Tribales en países independientes, y, de acuerdo con la interpretación de la Corte Constitucional colombiana, éste Convenio incorpora la obligación de respeto de los derechos de las comunidades afrocolombianas en cuanto a sus condiciones sociales, económicas y culturales; debemos sumar también el Estatuto de Roma de la Corte Penal Internacional, etc.

- Los Instrumentos de Protección de los Derechos de los Niños, dentro de los cuales se encuentran la Declaración de Ginebra de 1924 sobre Derechos del Niño; la Declaración de los Derechos del Niño adoptada por la Asamblea General de las Naciones Unidas el 20 de noviembre de 1959 y, reconocida en la Declaración Universal de Derechos Humanos; las Reglas de Beijing y Reglas de las Naciones Unidas para la Protección de Menores Privados de la Libertad; la Convención Internacional sobre Derechos del Niño, etc.; la Declaración de Derechos del Retrasado Mental; la Declaración de Derechos de los Impedidos de las Naciones Unidas; el Programa de Acción Mundial para las Personas con Discapacidad; los Principios para la Protección de los Enfermos Mentales y para el Mejoramiento de la Salud Mental; la Convención Interamericana para la Eliminación de todas las formas de Discriminación contra las Personas con Discapacidad, etc.

Sin desconocer también, como ocurrió en Francia, que la Declaración de los Derechos del Hombre y del Ciudadano es parte histórica de nuestro bloque de constitucionalidad, desde que sus principios fueron incorporados en nuestras primeras constituciones provinciales del siglo XIX. La aplicación de estos tratados ha supuesto una reelaboración de la jurisprudencia "sobre ideas, métodos y conceptos jurídicos, que en muchos casos se encuentran ya presentes de manera previa y como latente dentro de la tradición jurídica occidental", así como también el "conjunto de

43 Sin embargo, posee dos fallos contradictorios de la Corte Constitucional colombiana. En el primero se excluye del bloque de constitucionalidad: Sentencia C-161 de 2000 y, luego, en la Sentencia C-466 de 2008, se dispuso la pertenencia de este Convenio al bloque de constitucionalidad. 
instrumentos internacionales de contenido y efectos jurídicos variados (tratados, convenios, resoluciones y declaraciones). Su evolución dinámica ha ejercido un impacto positivo en el Derecho Internacional, en el sentido de afirmar y desarrollar la aptitud de este último para regular las relaciones entre los estados y los seres humanos bajo sus respectivas jurisdicciones" 44 .

El diálogo jurisprudencial de la $\mathrm{CIDH}$ con los jueces de los Estados Parte resalta la importancia que para las obligaciones internacionales de los Estados posee el control de convencionalidad. Incluso las constituciones nacionales son susceptibles del control de convencionalidad, pues al referirse la $\mathrm{CIDH}$ a las "leyes internas", se aplicarían también esas decisiones sobre la propia Norma de Normas, como lo indicó en la Opinión Consultiva O.C.-4/84 de 11 de enero de 1984. Basta citar como ejemplo el Caso Olmedo Bustos "La Última Tentación de Cristo" vs. Chile, donde se decidió que el Estado debía "modificar su ordenamiento jurídico interno, en un plazo razonable, con el fin de suprimir la censura previa" ${ }^{5}$; no obstante que, en el caso de Colombia, la Sala Plena de la Corte Constitucional ha sostenido, en la Sentencia C-941 de 201046, que "La Corte Constitucional no es juez de convencionalidad, esto es, no está llamada a verificar la concordancia abstracta de la legislación nacional con los tratados internacionales que obligan al Estado", dejando en claro que la $\mathrm{CADH}$ se integra al bloque de constitucionalidad ${ }^{47}$, pero "ello no significa que adquiera el rango de norma supraconstitucional ${ }^{48}$.

Algo importante para tener en cuenta es que en Colombia se ha hablado de un estado de cosas inconstitucional y, de esa forma, la Corte ha mencionado los siguientes parámetros como determinantes de la procedencia de un estado de cosas inconstitucional:

1) La vulneración masiva y generalizada de varios derechos constitucionales que afecta a un número significativo de personas.

2) La prolongada omisión de las autoridades en el cumplimiento de sus obligaciones para garantizar estos derechos.

44 Corte IDH. Opinión Consultiva O.C.-17/02, "Condición jurídica y derechos humanos del niño", solicitada por la Comisión IDH, 28 de agosto de 2002, Serie A, \# 17.

45 Caso Olmedo Bustos "La Última Tentación de Cristo" con Chile Corte IDH, sentencia de fondo, reparaciones y costas de 5 de febrero de 2001, Serie C, \# 73, presupuesto resolutivo 4.

46 Corte Constitucional de Colombia. Sentencia C-941 de 2010, M.P. Jorge Iván Palacio Palacio.

47 Olano (2005), p. 235.

48 BAZÁN (2013), p. 312. 
3) La adopción de prácticas inconstitucionales, como la exigencia de incorporar la acción de tutela como parte del procedimiento para garantizar el derecho conculcado.

4) La no expedición de medidas legislativas, administrativas o presupuestales necesarias para evitar la vulneración de los derechos.

5) La existencia de un problema social cuya solución compromete la intervención de varias entidades, para la adopción mancomunada de un conjunto de medidas multisectoriales que [...] exige un nivel de recursos que demanda un esfuerzo presupuestal adicional importante.

6) Si todas las personas afectadas por el mismo problema acudieran a la acción de tutela para obtener la protección de sus derechos, se produciría una mayor congestión judicial.

De otro lado, la Corte Constitucional ha ideado dos mecanismos para vigilar el cumplimiento efectivo de las órdenes impartidas en las sentencias estructurales: las salas y los autos de seguimiento ${ }^{49}$, lo cual es similar al proceso de verificación de las decisiones de convencionalidad que realiza la CIDH.

Los Estados Partes del Sistema Interamericano "han asumido que si su ordenamiento jurídico interno no se adecua a las obligaciones generales, deben adoptar las medidas necesarias para concretar dicha adecuación, lo que implica modificar la Constitución, o adoptar preceptos legales, resoluciones administrativas, desarrollar prácticas políticas y administrativas, como asimismo emplear las atribuciones jurisdiccionales de los tribunales en su respectivo ámbito competencial para concretar los estándares mínimos convencionales" 50 .

$\mathrm{La} \mathrm{CIDH}$ ha pedido en casos como el Radilla Pacheco vs. México que "al momento de resolver un caso o tomar cualquier decisión estatal lo que debe hacerse es determinar los hechos relevantes sobre los cuales debe tomarse una cierta decisión; luego, analizar el sistema normativo que se va a utilizar y es aquí donde tiene su primer impacto el control de convencionalidad, ya que se amplía o robustece el sistema normativo aplicable pues no sólo queda limitado a las normas de origen interno (constitucionales, legales y reglamentarias), sino también a aquellas de origen internacional que han sido recepcionadas internamente (en este caso la $\mathrm{CADH}) " 51$.

49 Osuna (2015), pp. 112-113.

50 Nogueira (2013), p. 963.

51 NASH (2013), p. 500. 
En México se fijaron unas pautas para la aplicación de las decisiones de la $\mathrm{CIDH}$, debido a las implicaciones que éstas poseen, puesto que ese primer fallo revolucionó la Suprema Corte de Justicia de la Nación (SCJN), pues no se sabía de qué forma habría de cumplir con lo decidido. Por tanto, esas reglas surgieron de un proceso incidental que tuvo como ponente a la Ministra Margarita Beatriz Luna Ramos, quien, junto con el plenario, consideró que:

- Existe un modelo de control concentrado en los órganos del Poder Judicial de la Federación con vías directas de control: acciones de inconstitucionalidad, controversias constitucionales y amparo directo e indirecto; y en segundo término, el control por parte del resto de los jueces del país en forma incidental durante los procesos ordinarios en los que son competentes, esto es, sin necesidad de abrir un expediente por cuerda separada.

- Las sentencias condenatorias de la CIDH en las que el Estado mexicano sea parte son obligatorias en sus términos para el Poder Judicial de la Federación.

- Los jueces deberán llevar a cabo un control de convencionalidad ex officio en un modelo de control difuso de constitucionalidad.

- Todas las autoridades del país en el ámbito de sus competencias tienen la obligación de aplicar las normas correspondientes, haciendo la interpretación más favorable a la persona para lograr su protección más amplia, sin tener la posibilidad de inaplicar o declarar la incompatibilidad de las mismas. ${ }^{52}$

Por ejemplo, el valor del precedente ${ }^{53}$ y la interpretación auténtica fueron objeto de pronunciamiento en la Corte Constitucional de Colombia, cuando por medio de la Sentencia C-806 de 200154, se precisó:

... las leyes que se limitan a declarar el sentido de otras leyes, se entenderán incorporadas en éstas; pero no afectarán en manera alguna los efectos de las sentencias ejecutoriadas en el tiempo intermedio, con lo cual se incorpora en nuestro ordenamiento la denominada interpretación auténtica o legislativa que, como su nombre lo indica, es la realizada por medio de una ley con el propósito de señalar el sentido en que debe entenderse una ley anterior cuyo enunciado se presta a dudas.

Al establecer el sentido y alcance de una ley el legislador no hace una nueva declaración de voluntad, porque simplemente se limita a corroborar la expresada en la ley interpretada. Además, como se supone que la ley interpretativa forma un solo cuerpo con la ley interpretada (se incorpora a ésta, según lo prescribe el artículo 14 del Código Civil), ella debe

52 BAZÁN (2014), p. 313.

53 Olano (2011).

54 Corte Constitucional de Colombia, Sentencia C-806 de 2001, M.P. Dra. Clara Inés Vargas Hernández. 
ser aplicada desde la vigencia de esta última, sin perjuicio de los efectos de las sentencias judiciales ejecutoriadas en el interregno.

La jurisprudencia constitucional se ha referido a las leyes interpretativas haciendo énfasis en su fuerza vinculante y en los requisitos constitucionales que debe cumplir su expedición.

El principio de respeto por los tratados internacionales puede darse a través de dos vías, según el exmagistrado de la Corte Constitucional colombiana Marco Gerardo Monroy Cabra55:

- Interpretación auténtica hecha por los Estados Parte en el tratado. A su vez, esta interpretación puede hacerse por un acuerdo interpretativo, bilateral o multilateral, o puede ser tácita cuando resulta de la ejecución concordante del tratado por las partes contratantes.

- Interpretación jurisdiccional internacional. Esta interpretación es realizada por órganos internacionales, tribunales y árbitros internacionales, a quienes se someta el litigio referente a la determinación del sentido y alcance de un tratado.

La interpretación por parte de los jueces supone más recientemente cumplir con los siguientes pasos:

- Interpretación conforme en sentido amplio, que significa que se debe interpretar el orden jurídico a la luz y conforme a los derechos humanos establecidos en la Constitución y en los tratados internacionales, favoreciendo en todo tiempo la protección más amplia de las personas.

- Interpretación conforme en sentido estricto, para casos en los que existen varias interpretaciones jurídicamente válidas de un determinado precepto, supuesto en el que los jueces deben, partiendo de la presunción de constitucionalidad de las leyes, preferir aquella interpretación que hace la ley acorde con los derechos humanos establecidos en la Constitución y en los tratados internacionales. ${ }^{56}$

Así, en cuanto a la jurisprudencia de la CIDH, ésta contiene la interpretación auténtica de los derechos contenidos en la CADH. Dicha jurisprudencia ostenta "carácter vinculante" 57 y, por tanto, se genera en relación con la CADH y su valor intrínseco, y a las decisiones de la CIDH se debe un respeto y una obligación de garantizar que su contenido se aplique en el ordenamiento de los Estados

55 Monroy Cabra (1997), pp. 58-59.

56 BAZÁN (2014), p. 314.

57 BAZÁN (2014), p. 311. 
Parte, no obstante un "margen de apreciación" que la doctrina ha creado para evitar en ocasiones dificultades operativas en cuanto a la aplicación del control de convencionalidad.

Por eso es claro que si el intérprete llega a la conclusión "de que una norma interna o una interpretación distinta a la dada por la Corte es una mejor interpretación, es posible preferir la protección nacional, pero el intérprete deberá explicar de qué forma se da esta mejor protección" 58 .

Bien lo ha dicho la CIDH en la Opinión Consultiva O.C.-2/82 cuando afirmó que la $\mathrm{CADH}$ y el corpus iuris interamericano, o un ius commune, 59 "no son tratados multilaterales del tipo tradicional, concluidos en función de un intercambio recíproco de derechos para el beneficio mutuo de los estados contratantes; por el contrario, cuando los Estados aprueban un tratado sobre derechos humanos quedan sometidos a un ordenamiento legal dentro del cual asumen diversas obligaciones en relación con los individuos bajo su jurisdicción y no frente a otros Estados" 60.

$\mathrm{Y}$ es que no es irrelevante el que la CIDH haya hablado del efecto útil de sus decisiones, así como de los compromisos internacionales sobre derechos humanos en general, y de la $\mathrm{CADH}$ en particular $^{61}$, de manera que ese efecto útil "no quede mermado o anulado por la aplicación de normas o prácticas internas contrarias al objeto y al fin del instrumento internacional o del estándar internacional de protección de los derechos humanos" 62 .

La eficacia vinculante de la sentencia de la $\mathrm{CIDH}$ que establece la responsabilidad internacional de un Estado que fue parte material de la controversia, y en la que tuvo adecuada y oportuna defensa en juicio, no sólo se proyecta hacia la parte "resolutiva" o "dispositiva" del fallo, sino que alcanza los razonamientos, argumentos y consideraciones que fundamentan y dan sentido a la decisión al

\footnotetext{
58 NASH (2013), p. 505.

60 Corte IDH. Opinión Consultiva O.C.-2/82.

61 BAZÁN (2014), p. 331.

62 BAZÁN (2014), p. 332
}

59 El profesor mexicano Juan Pablo Pampillo Baliño, en su discurso de posesión como Miembro Correspondiente de la Academia Colombiana de Jurisprudencia en 2013, dijo que "La conformación de un derecho comunitario -ius communitatis- americano requerirá también de la armonización de los derechos propios -iura propria- de la región (bloques, países y regiones), que eventualmente, habrá de generar el surgimiento de un derecho común -ius commune- propio de los países de nuestro continente". 
implicar la sentencia un acto jurisdiccional que involucra, en general, "la decisión" como acto jurisdiccional decisorio ${ }^{63}$.

Eso puede comprobarse en múltiples decisiones de la CIDH, como por ejemplo, los casos Heliodoro Portugal vs. Panamá de 2008; Boyce y otros vs. Barbados $^{64}$, y en las citadas Trabajadores Cesados del Congreso (Aguado Alfaro y otros) vs. Perú y particularmente, en el caso Almonacid Arellano y otros vs. Chile, cuando la CIDH expresó en el párrafo 87 lo siguiente:

En el derecho de gentes, una norma consuetudinaria prescribe que un estado que ha ratificado un tratado de derechos humanos debe introducir en su derecho interno las modificaciones necesarias para asegurar el fiel cumplimiento de las obligaciones asumidas. Esta norma es universalmente aceptada, con respaldo jurisprudencial. La Convención Americana establece la obligación general de cada Estado Parte de adecuar su derecho interno a las disposiciones de dicha Convención, para garantizar los derechos en ella consagrados. Este deber general del estado Parte implica que las medidas de derecho interno han de ser efectivas (principio del "effet utile"). Esto significa que el Estado ha de adoptar todas las medidas para que lo establecido en la Convención sea efectivamente cumplido en su ordenamiento jurídico interno, tal como lo requiere el artículo $2^{\circ}$ de la Convención. Dichas medidas sólo son efectivas cuando el estado adapta su actuación a la normativa de protección de la Convención".

Lo anterior ha quedado ratificado por la $\mathrm{CIDH}$ en la opinión Consultiva OC-14/94, al manifestar allí que: "Según el derecho internacional las obligaciones que éste impone deben ser cumplidas de buena fe y no puede invocarse para su incumplimiento el derecho interno. Estas reglas pueden ser consideradas como principios generales del derecho y han sido aplicadas, aun tratándose de disposiciones de carácter constitucional, por la Corte Permanente de Justicia Internacional y la Corte Internacional de justicia... Asimismo estas reglas han sido codificadas en los artículos 26 y 27 de la Convención de Viena sobre el Derecho de los Tratados de 1969"65, y, en más de veinte decisiones contenciosas, la $\mathrm{CIDH}$ se ha pronunciado sobre diversos aspectos del control de convencionalidad,

63 Ferrer Mac-Gregor (2013), p. 634.

64 Aquí se dijo que el objetivo del control de convencionalidad está acorde o no con la CADH. Si lo es, el juez la aplica, si no lo es, no lo hace por resultar inconvencional, que produce el deber judicial de inaplicación del precepto objetado.

65 Corte IDH. Opinión Consultiva OC-14/94, Responsabilidad internacional por expedición y aplicación de leyes violatorias de la Convención (arts. $1^{\circ}$ y 20\%), de 9 de diciembre de 1994, solicitada por la Comisión Interamericana de Derechos Humanos, serie A, \# 14, párrafo 35. 
involucrando "la responsabilidad internacional de trece Estados distintos: Argentina, Barbados, Bolivia, Brasil, Chile, Colombia, Guatemala, México, Panamá, Paraguay, Perú, Uruguay y Venezuela; lo que significa que más de la mitad de los Estados Parte en la Convención que han reconocido la jurisdicción contenciosa de la Corte IDH. Desde el Caso Cabrera García y Montiel Flores vs. México de 2010, la Corte IDH ha venido ejemplificando la manera en que tribunales de la más alta jerarquía en varios Estados de la región se refieren al carácter vinculante de las sentencias del Tribunal interamericano y la manera en que han recibido o aplicado el control de convencionalidad teniendo en consideración la jurisprudencia interamericana..." 66 .

Para cerrar, cabe indicar, como lo hace el exjuez de la CIDH Sergio García Ramírez, que la CIDH "es un tribunal permanente (ejerce su jurisdicción en forma ininterrumpida, sin perjuicio de que sus integrantes se reúnan materialmente en períodos de sesiones en San José o en otras ciudades de América) con vocación hacia los casos paradigmáticos, para la emisión de criterios jurisdiccionales que sean recibidos y multiplicados en el ámbito interno a través de diversos mecanismos de recepción. Uno de éstos es el control de convencionalidad" 67.

Además, no debe olvidarse que cuando llega un caso al sistema interamericano de protección de derechos fundamentales y el Estado es condenado, es porque ha fallado una instancia jurisdiccional del sistema nacional, ya que para acceder al sistema interamericano deben haberse agotado previamente las instancias jurisdiccionales internas ${ }^{68}$.

\section{PRINCIPIOS}

Es conveniente recordar la figura del profesor Rodolfo Piza Escalante ${ }^{69}$, magistrado de la Sala Constitucional de Costa Rica y Presidente de la Corte Interamericana de Derechos Humanos, quien hizo diversas contribuciones al Derecho de los derechos humanos, rescatándose de la doctrina los apartes de una intervención que realizara en 1982 en Nueva York. De ella surgieron quince principios fundamentales del Derecho de los derechos humanos, que por su importancia me permito transcribir y complementar, ya que la aplicación de estos principios en

\footnotetext{
66 Ferrer Mac-Gregor (2013), pp. 668-669.

67 García Ramírez (2013), p. 775.

68 Nogueira (2013), p. 917.

69 Ventura (2003), pp. 270-275.
} 
los que se ventile la violación o amenaza de violación de derechos fundamentales internos o internacionales, constituye un condicionamiento importante para los tribunales constitucionales que siguen la doctrina de la Corte Interamericana y, por ende, de relevancia directa para el Derecho Procesal Constitucional, así como también para el control de convencionalidad:

Principio prohomine: Las normas de derechos humanos deben interpretarse y aplicarse extensivamente en todo cuanto favorezca al ser humano y al pleno goce de los derechos humanos, y restrictivamente en todo lo que los excluya, restrinja y condicione o exceptúe. Los conflictos de normas deben resolverse siempre en el sentido más favorable al ser humano.

Por ejemplo, en 1992, la Sala Constitucional de Costa Rica dispuso que ${ }^{70}$ :

"El orden público, la moral y los derechos de terceros deben ser interpretados y aplicados rigurosamente, sin licencias que permitan extenderlos más de su sentido específico; sentido que, a su vez, debe verse en armonía con el principio pro libertate, el cual, junto con el principio pro homine, constituye el meollo de la doctrina de los derechos humanos; según el primero, debe interpretarse extensivamente todo lo que favorezca y restrictivamente todo lo que limite la libertad; según el segundo, el derecho debe interpretarse y aplicarse siempre de la manera que más favorezca al ser humano".

Principio de accionabilidad: Tratándose de aquellos derechos humanos y libertades fundamentales inmediatamente atribuidos al ser humano, todo ser humano debe tener garantizado un derecho de acción autónomo para exigir el respeto y cumplimiento de tales derechos o libertades, tanto ante tribunales independientes internos, como ante organismos internacionales apropiados.

Tratándose de aquellos derechos humanos que sean legal o naturalmente dependientes de una acción progresiva por parte del Estado, cada uno y todo individuo debe gozar por lo menos: i) de un derecho de petición para demandar el cumplimiento de tales derechos ante las autoridades nacionales; ii) de un derecho de acción autónomo para oponerse a cualquier actividad por parte del Estado que pueda impedir o retrasar el cumplimiento de tales derechos, como ante organismos internacionales apropiados.

Principio de exigibilidad: Sin perjuicio de su indivisibilidad e interdependencia, cada uno y todo derecho humano es disfrutable y exigible por sí mismo, sin estar sujeto a ninguna condición o restricción derivada de otros derechos humanos, salvo en la medida prevista expresa y restrictivamente por el Derecho Internacional.

70 Hernández (1995), p. 94. 
Principio de expansibilidad: Los derechos humanos reconocidos por el Derecho internacional o nacional son mínimos y deben ser realizados de una manera expansiva, de manera que puedan ser ensanchados progresivamente mediante otros derechos humanos que se deriven de la dignidad intrínseca del ser humano.

Principio de fundamentalidad. Los derechos humanos son fundamentales, en el sentido de que se derivan de la intrínseca dignidad del ser humano y no de la voluntad de ninguna autoridad, la cual debe limitarse a reconocerlos, hacerlos efectivos y respetarlos.

Principio de humanidad (igualdad-no discriminación-): Los derechos humanos se atribuyen a cada uno y todo ser humano por la sola razón de serlo, por igual y sin discriminación alguna, salvo aquellas autorizadas expresa y restrictivamente por el Derecho Internacional.

Principio de imperatividad (Jus Cogens): El Derecho de los derechos humanos, en general, forma parte del Derecho Internacional General Imperativo (Jus Cogens). En consecuencia:

- Sus principios fundamentales, inclusive los contenidos en la Declaración Universal de los Derechos Humanos y otros documentos en materia de derechos humanos similarmente reconocidos por las Naciones Unidas, tienen el carácter y validez de las normas imperativas del Derecho Internacional (Jus Cogens), con los efectos atribuidos a los mismos por la Convención de Viena sobre el Derecho de los Tratados de 1969;

- El mismo carácter, validez y efectos deben darse a los principios fundamentales del Derecho de los Derechos Humanos en los sistemas regionales reconocidos por las Naciones Unidas;

- Determinados derechos humanos específicos, reconocidos por los pactos y convenciones internacionales adoptados dentro del Sistema de las Naciones Unidas o, en su caso, dentro de los sistemas regionales reconocidos por aquéllas, deberán también ser considerados como parte de las normas imperativas del Derecho Internacional, en especial aquellos que no pueden ser condicionados o suspendidos por la legislación interna o por actos autorizados por ésta;

- Los derechos humanos solamente deben ser limitados, condicionados, exceptuados o suspendidos en los casos y en la medida expresa y restrictivamente autorizados por los correspondientes instrumentos del Derecho Internacional;

- Cualquier norma o acto, tanto internacional como nacional, que viole, suprima, modifique o restrinja derechos humanos reconocidos por una norma o principio de mayor rango de conformidad con el Derecho Internacional, salvo en la medida autorizada expresa y restrictivamente por éste, será nula e ineficaz. 
Principio de incondicionalidad: Los derechos humanos implican deberes correspondientes del ser humano para consigo mismo, para con los demás hombres, para con las comunidades nacional e internacional y para con la humanidad entera, pero la titularidad y ejercicio de tales derechos no está condicionada al cumplimiento de aquellos deberes, salvo en la medida prevista expresa y restrictivamente por el Derecho Internacional.

Principio de irretroactividad-retroactividad: Cualquier norma que suprima, restrinja o condicione los derechos humanos es irretroactiva. Cualquier norma que los reconozca, aplique, garantice o extienda es aplicable inmediatamente, aun respecto de situaciones consolidadas con anterioridad a la misma.

Principio de necesidad (inalienabilidad): Los derechos humanos son indispensables para la dignidad fundamental del ser humano y para la existencia misma de la humanidad; por lo tanto, son inalienables, imprescriptibles e irrenunciables, salvo en el tanto previsto expresa y restrictivamente por el Derecho Internacional.

Principio de prevalencia: Los principios y normas de derechos humanos son de orden público y deben prevalecer sobre cualesquiera otros principios o normas de rango igual correspondientes a cualquiera otra disciplina del Derecho. Lo cual sugiere una jerarquización para garantizar el Derecho.

Principio de razonabilidad: Las normas de derechos humanos deben interpretarse y aplicarse de la manera que más razonablemente conduzca al cumplimiento pleno de su propósito fundamental de promover y proteger al ser humano en su integridad.

Toda excepción, suspensión, limitación o condición de los derechos humanos autorizada por el Derecho debe restringirse a lo razonablemente necesario en una sociedad democrática, para proteger los derechos humanos de otras personas, para garantizar la seguridad de todos ellos o para cumplir las justas demandas del bien común.

La discrecionalidad en el campo de los derechos humanos debe estar limitada, en general, por los principios del Derecho de los Derechos Humanos, y sujeta a fiscalización judicial en cuanto a su razonabilidad fundamental, su justicia y el respeto a la dignidad humana.

Toda conclusión a la que se llegue será favorable a la viabilidad del proceso constitucional siempre que no resulte patente la inconsistencia del razonamiento que lleva al órgano judicial a individualizar cierta regla general como norma de la decisión ${ }^{71}$.

71 JiMÉNEZ (1998), p. 195. 
Principio de transnacionalidad (interacción): Los derechos humanos reconocidos por el Derecho Internacional deben ser vinculantes por sí mismos en el Derecho interno, con el rango de las normas constitucionales.

Los derechos humanos reconocidos por el Derecho interno deben ser vinculantes para el Estado correspondiente, como normas de carácter internacional, mientras no sean incompatibles con el Derecho Internacional.

La misma interacción debe existir entre los derechos humanos reconocidos por el Derecho Internacional universal y regional, con respecto a los Estados que pertenezcan a ambos.

Principio de universalidad (internacionalidad): Los derechos humanos son universales, en el sentido de que su reconocimiento, aplicación y respeto son obligaciones intrínsecas de cada ser humano, sociedad o Estado, y de la comunidad internacional, y de que ellos caen bajo el ámbito y jurisdicción tanto del derecho nacional como del internacional.

Principios de indivisibilidad e interdependencia: Los derechos humanos son indivisibles e interdependientes, en el sentido de que son atributos coherentes para la elevación y respeto de la dignidad humana y para el desarrollo armónico de todos los seres humanos en conjunto; por tanto, cada derecho humano debe hacerse eficaz de una manera congruente con los demás derechos y ninguno de una manera incongruente con los derechos de los demás seres humanos.

La protección procesal de los derechos humanos impone, en consecuencia, que exista el proceso adecuado a los fines a tutelar y de ahí que sea necesario el conocimiento de estos principios para su adecuada aplicación.

\section{CONCLUSIÓN}

El centro de nuestro estudio es el control de convencionalidad, que no está incluido en ningún tratado sobre derechos humanos, pero, por creación pretoriana, rige dentro del Sistema Interamericano de Derechos Humanos, aceptando la competencia contenciosa de la $\mathrm{CIDH}$ y reconociendo que ella posee facultades jurisdiccionales para emitir decisiones obligatorias para los Estados Parte del Sistema.

Se puede evitar por los Estados Parte ser sancionados internacionalmente disponiendo el respeto por el principio pacta sunt servanda y la creación de estándares de aplicabilidad de las decisiones de la CIDH y compatibilizando la normatividad interna con las disposiciones que forman parte de la CADH y su bloque de convencionalidad, debido a las disposiciones de los artículos 1.1, 2 y 29 de la Convención, así como a los principios del derecho internacional público universalmente aceptados. 
El control de convencionalidad puede ocasionar inconvenientes operativos en los sistemas jurídicos nacionales por el desconocimiento del bloque de derechos humanos y de la jurisprudencia de la CIDH por parte de quienes deban conocer estas disposiciones, frente a lo cual debe aplicarse la interpretación más favorable conforme al principio pro personae, para evitar su afectación con actuaciones anticonvencionales, por eso su aplicación ha de hacerse prudentemente.

El control de convencionalidad "entraña la aplicación del orden supranacional, aceptado por cada país y colectivamente formulado, en lo que toca a definiciones de derechos y libertades, asignación de responsabilidades y consecuencias jurídicas de los hechos ilícitos contraventores de aquel orden. Representa, además, congruencia con un propósito innovador o protagónico; puede ser el fruto de un activismo bien entendido, pero no podría (o no debería) conducir a un activismo desenfrenado. Así las cosas, el control de convencionalidad no dispersa ni atomiza, sino que reúne y sistematiza (aunque algunos consideren que puede darse una fragmentación jurisprudencial). En su propia vertiente, el control de convencionalidad se halla al servicio de la justicia y de la seguridad jurídica. Parece innecesario decirlo, pero es conveniente insistir en ello: no debe culminar en siembra de injusticia, ni de inseguridad general o particular, sino que debe aplicarse con prudencia"72. Y, si bien la jurisprudencia interamericana no se ha referido en sí a un sistema difuso o concentrado de control de convencionalidad, la decisión finalmente corresponde a cada país "en función de sus propias circunstancias y de la mejor protección de los derechos humanos". ${ }^{73}$

Las autoridades domésticas "deben establecer, regular y evaluar el sistema de control constitucional convencional más adecuado, conforme a las condiciones del país a fin de evitar que las sentencias de la Corte Interamericana y la propia Convención Americana devengan en 'letra muerta'"74.

Independientemente de las reformas legales que realice cualquiera de los Estados Parte en su normatividad interna, les corresponde a las autoridades judiciales (y demás autoridades públicas), con base en el control de convencionalidad, aplicar las disposiciones de la CADH y las decisiones imperativas de la CIDH dentro del marco de las competencias internas de cada operador de justicia.

Así las cosas, "cuando un juez interno aplique la jurisprudencia internacional para resolver los casos sobre los que se vea llamado a pronunciarse pese a que las

72 García y Palomino (2013), p. 226.

73 García Ramírez y Morales Sánchez (2013), p. 632.

74 García Ramírez y Morales Sánchez (2013), p. 624. 
partes procesales no hayan invocado dicha jurisprudencia internacional, que a la postre sea determinante para la resolución de dichos casos (, ya que) la aplicación de las normas internacionales por los jueces nacionales y los demás operadores jurídicos se considera la 'piedra de toque' del cumplimiento efectivo del derecho internacional como tal”75. Eso es lo que se ha denominado la aplicación del principio jura novit curia. ${ }^{76}$

Esto no implica un fallo extra petita por parte del juez o un prevaricato por la autoridad pública o judicial, sino el seguimiento de la interpretación auténtica, criterio relevante que resalta la jurisprudencia de la CIDH y su carácter vinculante. En caso de haber más de un pronunciamiento de la CIDH, siempre debe preferirse el que de mejor manera proteja los derechos de la persona para el caso concreto.

Por tanto, el control de convencionalidad se entiende dentro del marco del Estado Social de Derecho, que pasa a ser un Estado convencional, legal y constitucional, con efectos para el caso concreto (vinculación directa inter partes), en el cual, para la consolidación de una recta y efectiva justicia, también se producen efectos vinculantes para los Estados Parte signatarios de la $\mathrm{CADH}$, en lo que respecta a la interpretación que dicho Tribunal efectúa de las normas convencionales (vinculación directa erga omnes).

La doctrina legal (o judicial) de ese cuerpo jurisdiccional es obligatoria (vinculante) para el conjunto de los países plegados al sistema en cuanto a la hermenéutica que él hace de las normas regionales interpretadas (res interpretata) ${ }^{77}$.

Aunque el control de convencionalidad es difuso en las jurisdicciones nacionales y concentrado en la $\mathrm{CIDH}$, siempre y cuando haya habido un acto de incorporación de la CADH, el Poder Judicial debe realizar una "especie" de control de convencionalidad y desarrollar no sólo un control de constitucionalidad, sino también de convencionalidad, incluso de oficio (y también a petición de parte), involucrando a los jueces y órganos vinculados a la administración de justicia en todos los niveles y a cualquier autoridad pública y no sólo al Poder Judicial en el proceso de fiscalización convencional, adecuando las interpretaciones judiciales y administrativas y de las garantías judiciales a los principios establecidos en la jurisprudencia de la CIDH.

75 JimÉNEZ (2009), p. 542.

76 BAZÁN (2014), p. 306.

77 García Ramírez (2013), p. 905. 
BiBLIOGRAFÍA

Álvarez Ledesma, Mario I.; Cippitani, Roberto (2013): Diccionario Analítico de Derechos Humanos e Integración Jurídica. (Universitá degli Studi di PavíaTecnológico de Monterrey. Peruggia).

Ambos, Kai; Malarino, Ezequiel; Steiner, Christian (editores) (2013): Sistema Interamericano de Protección de los Derechos Humanos y Derecho Penal Internacional - Tomo III. (Georg-August-Universitát-Göttingen y Fundación Konrad Adenauer Stiftung, Bogotá, D.C.).

BAZÁN, Víctor (2014): Control de las Omisiones Inconstitucionales e Inconvencionales. Recorrido por el derecho y la jurisprudencia americanos y europeos. (Fundación Konrad Adenauer Stiftung, Bogotá, D.C.).

BAZÁN, Víctor (2013): Algunos retos temáticos para la justicia constitucional en América Latina, en: Eto Cruz, Gerardo (2013): Treinta años de jurisdicción constitucional en el Perú. Tomo I, Tribunal Constitucional (Centro de Estudios Constitucionales, Lima, p. 233).

Ferrer Mac-Gregor, Eduardo y Herrera García, Alfonso (Coordinadores) (2013): Diálogo Jurisprudencial en Derechos Humanos entre Tribunales Constitucionales y Cortes Internacionales. Instituto Iberoamericano de Derecho Constitucional, Corte Interamericana de Derechos Humanos (Universidad Nacional Autónoma de México, Tirant lo Blanch, México, D.F).

Ferrer Mac-Gregor, Eduardo (2013): Eficacia de la Sentencia Interamericana y la cosa juzgada internacional: vinculación directa hacia las Partes (res iudicata) e indirecta hacia los estados Parte de la Convención Americana (res interpretata). Sobre el cumplimiento del Caso Gelman vs. Uruguay, en: Ferrer MAC-Gregor, Eduardo y Herrera García, Alfonso (Coordinadores). Diálogo Jurisprudencial en Derechos Humanos entre Tribunales Constitucionales y Cortes Internacionales. Instituto Iberoamericano de Derecho Constitucional, Corte Interamericana de Derechos Humanos (Universidad Nacional Autónoma de México, Tirant lo Blanch, México, D.F).

García Belaunde, Domingo y Palomino Manchego, José Félix (2013): El control de convencionalidad en el Perú, en: AA.VV. Controle de Convencionalidade. Um panorama latino-americano. Luiz Guilherme Marinoni y Valerio de Olivera Mazzuoli (coords.). (Brasilia: Gazeta Jurídica Editora).

GarCía RAmírez, Sergio (2013): El control judicial interno de convencionalidad, en: Ferrer Mac-Gregor, Eduardo y Herrera García, Alfonso (Coordinadores). Diálogo Jurisprudencial en Derechos Humanos entre Tribunales Constitucionales 
y Cortes Internacionales. Instituto Iberoamericano de Derecho Constitucional, Corte Interamericana de Derechos Humanos, (Universidad Nacional Autónoma de México, Tirant lo Blanch, México, D.F).

García Ramírez, Sergio y Morales Sánchez, Julieta (2013): El Control de Convencionalidad: Construcciones y dilemas, en: Ето CRUZ, Gerardo: Treinta años de jurisdicción constitucional en el Perú. Tomo II (Tribunal Constitucional - Centro de Estudios Constitucionales, Lima).

Hernández Valle, Rubén (1995): Derecho Procesal Constitucional. (Editorial Juricentro. San José, Costa Rica).

HeRnández Valle, Rubén (2013): Apuntaciones sobre el control de convencionalidad en América Latina, en: ETO CRUZ, Gerardo: Treinta años de jurisdicción constitucional en el Perú. Tomo II (Tribunal Constitucional - Centro de Estudios Constitucionales, Lima).

JimÉnez CAMPo, Javier (1998): Sobre la Cuestión de Inconstitucionalidad, en: RuBIO Llorente, Francisco y Jiménez CAMPO, Javier. Estudios sobre jurisdicción constitucional. (Editorial MacGraw Hill, Colección Ciencias Jurídicas, Madrid).

JimÉNEZ QUeSADA, Luis (2009): La vinculación del juez a la jurisprudencia internacional, en: Revenga SÁnchez, Miguel (coord.). El poder Judicial (Tirant lo Blanch, Valencia).

Monroy Cabra, Marco Gerardo (1997): Interpretación en derecho internacional. En: Hermenéutica jurídica. Homenaje al maestro Dario Echandía. (Ediciones Rosaristas, Bogotá, D.C.).

Nash Rojas, Claudio (2013): Control de convencionalidad. Precisiones conceptuales y desafios a la luz de la jurisprudencia de la Corte Interamericana de Derechos Humanos, en: Anuario de Derecho Constitucional Latinoamericano. Anuario 2013 (Universidad del Rosario, Fundación Konrad Adenauer Stiftung, Bogotá, D.C.), pp. 489-509.

Nogueira Alcalá, Humberto (2013): Los desafios del control de convencionalidad del corpus iuris interamericano para los tribunales nacionales, en especial, para los Tribunales Constitucionales, en: Ferrer Mac-Gregor, Eduardo y Herrera García, Alfonso (Coordinadores). Diálogo Jurisprudencial en Derechos Humanos entre Tribunales Constitucionales y Cortes Internacionales. Instituto Iberoamericano de Derecho Constitucional, Corte Interamericana de Derechos Humanos, Universidad Nacional Autónoma de México (Tirant lo Blanch, México, D.F.).

Olano García, Hernán Alejandro (2005): El bloque de constitucionalidad en Colombia, en Estudios Constitucionales, Universidad de Talca, (vol. 3 \# 1), pp. 231-242. 
Olano GarCía, Hernán Alejandro (2011): Del precedente constitucional al nuevo precedente contencioso administrativo, en: Estudios Constitucionales, Universidad de Talca, (vol. 9 \# 2), pp. 395-428.

Olano García, Hernán Alejandro (2009): Hermenéutica Constitucional. (Grupo Editorial Ibáñez, Bogotá, D.C.).

Osuna, Néstor. Las sentencias estructurales. Tres ejemplos en Colombia, en: BAZÁN, Víctor (editor académico) (2015): Justicia Constitucional y Derechos Fundamentales. La protección de los derechos sociales. Las sentencias estructurales. (Fundación Konrad Adenauer Stiftung y Facultad de Derecho Universidad de Chile. Bogotá, D.C.).

SAGUÉs, Néstor P. (2010): El control de convencionalidad, en: Von Bogdandy, Armin, Ferrer Mac-Gregor, Eduardo y Morantes Antoniazzi, Mariela (coords.). La justicia constitucional y su internacionalización ¿Hacia un Ius Constitutionale Commune en América Latina? (Instituto de Investigaciones Jurídicas de la UNAM, México, D.F), t. II, p. 452.

Ventura Robles, Manuel E. (2003): Los principales aportes del Juez Rodolfo E. Piza Escalante a la Corte Interamericana de Derechos Humanos (1979-1988). En: Justicia, Libertad y Derechos Humanos. Ensayos en homenaje a Rodolfo E. Piza Escalante. (Instituto Interamericano de Derechos Humanos, Sala Constitucional de la República de Costa Rica, Corte Interamericana de Derechos Humanos, Colegio de Abogados de la República de Costa Rica. San José, Costa Rica), Tomo I, pp. 270-275.

\section{JURISPRUDENCIA INTERAMERICANA CITADA}

Corte IDH. Caso Almonacid Arellano et al. vs. Chile, sentencia de 26 de septiembre de 2006, párrafo 124.

Corte IDH. Caso Atala Riffo vs. Chile, Sentencia de fondo, reparaciones y costas de 24 de febrero de 2012, Serie C \# 239, párrafo 284.

Corte IDH. Caso Cabrera García y Montiel Flores vs. México, Sentencia de excepción preliminar, fondo, reparaciones y costas, de 26 de noviembre de 2010, Serie C, \# 220, párrafo 225.

Corte IDH. Caso Cabrera García y Montiel Flórez vs. México, sentencia del 26 de noviembre de 2010, párrafo 225.

Corte IDH. Caso Gelman vs. Uruguay, sentencia de 24 de febrero de 2011, párrafo 239.

Corte IDH. Caso La Cantuta vs. Perú, sentencia de 29 de noviembre de 2006, párrafo 172. 
Corte IDH. Caso López Mendoza vs. Venezuela, Sentencia de fondo, reparaciones y costas de 1 de septiembre de 2011, Serie C, \# 233, párrafo 228.

Corte IDH. Caso Myrna Mack Chang vs. Guatemala, sentencia de 25 de noviembre de 2003, voto razonado del juez Sergio García Ramírez, párrafo 27.

Corte IDH. Caso Olmedo Bustos "La Última Tentación de Cristo" vs. Chile, sentencia de fondo, reparaciones y costas de 5 de febrero de 2001, Serie C, \# 73, presupuesto resolutivo 4 .

Corte IDH. Caso Tibi vs. Ecuador, sentencia de excepciones preliminares, fondo, reparaciones y costas de 7 de septiembre de 2004, Serie C, \# 114, párrafo 3. Corte IDH. Caso Trabajadores Cesados del Congreso (Aguado Alfaro et al.) vs. Perú, sentencia de 24 de noviembre de 2006, párrafo 128.

Corte IDH. Caso Vargas Areco vs. Paraguay, sentencia de fondo, reparaciones y costas de 26 de septiembre de 2006, Serie C, \# 155, párrafos 6 y 7.

Corte IDH. Caso Velásquez Rodríguez vs. Honduras, sentencia de 28 de julio de 1988, párrafo 166.

Corte IDH. Caso Villagrán Morales y otros (caso "niños de la calle") vs. Guatemala, sentencia de 26 de mayo de 2001.

Corte IDH. Opinión Consultiva O.C.-17/02, "Condición jurídica y derechos humanos del niño", solicitada por la Comisión IDH, 28 de agosto de 2002, Serie A, \# 17.

Corte IDH. Opinión Consultiva O.C.-2/82.

Corte IDH. Opinión Consultiva O.C.-14/94, Responsabilidad internacional por expedición y aplicación de leyes violatorias de la Convención (arts. $1^{\mathrm{o}} \mathrm{y}$ $2^{\circ}$ ), de 9 de diciembre de 1994, solicitada por la Comisión Interamericana de Derechos Humanos, serie A, \#14, párrafo 35.

Corte IDH. Supervisión de Cumplimiento de sentencia. Resolución de la Corte Interamericana de Derechos Humanos de 23 de noviembre de 2012. Caso Apiz Barrera et al. vs. Venezuela, considerandos 46 y 47.

\section{JURISPRUDENCIA COLOMBIANA CITADA}

Corte Constitucional, Sentencia C-806 de 2001, M.P. Clara Inés Vargas Hernández.

Corte Constitucional. Sentencia C-941 de 2010, M.P. Jorge Iván Palacio Palacio. Otras referencias Jurisprudenciales interamericanas de consulta sobre control de convencionalidad: 
Corte IDH. Caso Boyce y otros vs. Barbados, sentencia de 20 de noviembre de 2007. Serie C \# 169, párrafo 79.

Corte IDH. Caso Chocrón Chocrón vs. Venezuela, sentencia de 1 de septiembre de 2011. Serie C \# 233, párrafos 226 a 228.

Corte IDH. Caso Comunidad Indígena Xákmok Kásek vs. Paraguay, sentencia de 25 de agosto de 2010. Serie C \# 214, párrafo 311.

Corte IDH. Caso Fernández Ortega y otros vs. México, sentencia de 30 de agosto de 2010. Serie C \# 215, párrafo 236.

Corte IDH. Caso Fontevecchia y D’Amico vs. Argentina, sentencia de 29 de noviembre de 2011. Serie C \# 238, párrafos 93, 94 y 113.

Corte IDH. Caso Furlan y familiares vs. Argentina, sentencia de 31 de agosto de 2012. Serie C \# 246, párrafos 303 a 305.

Corte IDH. Caso Gomes Lund y otros ("Guerrilla do Araguaia”) vs. Brasil, sentencia de 24 de noviembre de 2010. Serie C \# 219, párrafos 49 y 106.

Corte IDH. Caso Gudiel Álvarez y otros ("Diario Militar") vs. Guatemala, sentencia de 20 de noviembre de 2012. Serie C \# 253, párrafo 330.

Corte IDH Caso Heliodoro Portugal vs. Panamá, sentencia de 12 de agosto de 2008. Serie C \# 186, párrafo 180.

Corte IDH. Caso Ibsen Cárdenas e Ibsen Peña vs. Bolivia, sentencia de 1 de septiembre de 2010. Serie C \# 217, párrafo 202.

Corte IDH. Caso Manuel Cepeda Vargas vs. Colombia, sentencia de 26 de mayo de 2010. Serie C \#213, párrafo 208.

Corte IDH. Caso Masacre de Santo Domingo vs. Colombia, sentencia de 30 de noviembre de 2012. Serie C \# 259, párrafos 142 a 144.

Corte IDH. Caso Masacres de Río Negro vs. Guatemala, sentencia de 4 de septiembre de 2012. Serie C \# 250, párrafo 262.

Corte IDH. Caso Rosendo Cantú y otra vs. México, sentencia de 31 de agosto de 2010. Serie C \# 216, párrafos 219 y 220.

Corte IDH. Caso Rosendo Radilla Pacheco vs. Estados Unidos Mexicanos, sentencia de 23 de noviembre de 2009. Serie C \# 209, párrafo 339.

Corte IDH. Caso Vélez Loor vs. Panamá, sentencia de 23 de noviembre de 2010. Serie C \# 218, párrafo 287. 